\title{
ПОЛУЧЕНИЕ ПРОИЗВОДНЫХ ПОЛИФУНКЦИОНАЛЬНЫХ КИСЛОТ И ИХ ФИЗИКО-ХИМИЧЕСКАЯ ХАРАКТЕРИСТИКА
}

Одним из широко применяемых методов при изучении структуры кислородсодержащих соединений $(-\mathrm{COOH},-\mathrm{OCO},-\mathrm{CHO},>\mathrm{C}=\mathrm{O}$ и $-\mathrm{NO}_{2}$ ) является восстановление - непосредственное гидрирование или декарбоксилирование кислот и их солей. Эти методы требуют в основном повышенных температур $\left(150-250^{\circ} \mathrm{C}\right)$ и сопровождаются побочными реакциями $\left[{ }^{1-3}\right]$. Так, при декарбоксилировании серебряных или ртутных солей алифатических и алициклических карбоновых кислот наряду с углеводородами в качестве побочного продукта получается соответствующий сложный эфир [4,5]. Из бариевой соли циклогексанкарбоновой кислоты образуется не циклогексан, а смесь дигидро- и тетрагидробензолов. При сухой перегонке кальциевых солей дикарбоновых кислот гладко получаются циклические кетоны [ $\left.{ }^{1}\right]$.

В отличие от приведенных примеров непосредственного превращения кислот в углеводороды Г. Э. Гойин при изучении нафтеновых кислот из фракции смазочных масел сырой нефти разработал новый метод последовательного превращения кислот в углеводороды в более мягких условиях через сложные эфиры, спирты и галоидные алкилы [ $\left.{ }^{6}\right]$. В. С. Робинзон, исследуя продукты перманганатного окисления керогена колорадского сланца, модифицировал метод Гойина [7,8]. Он превращал кислоты в сложные эфиры под действием н-бутанола. Бутиловые эфиры затем восстанавливались до спиртов литийалюминийгидридом $\left(\mathrm{LiAlH}_{4}\right)$. Полученные спирты далее превращались в иодиды реакцией с пероксидом фосфора, $85 \%$-ной фосфорной кислотой и иодистым калием, которые, в свою очередь, восстанавливались цинком и газообразным хлористым водородом.

Общий выход продуктов восстановления составил $36 \%$ от исходных кислот. Столь низкий выход В. С. Робинзон объясняет тем, что приблизителыно $50 \%$ продуктов окисления, состоящих из карбоновых кислот с числом углеродных атомов от 2 до 4, превращались в газы.

В продуктах окисления В. С. Робинзоном были установлены, кроме насыщенных $\left(\mathrm{C}_{2}-\mathrm{C}_{8}\right)$, н. кислоты $\left(\mathrm{C}_{16}-\mathrm{C}_{30}\right)-1 \%$, изопарафиновые $1 \%$, циклопарафиновые (1-6 колец) - $14 \%$, ароматические (1-2 кольца) $-6 \%$ и гетероциклические кислоты - 19\% от суммы исходных продуктов.

Полифункциональные кислоты (ПФК), образующиеся при азотнокислом окислении керогена сланца-кукерсита, термолабильны и не перегоняются без разложения в вакууме [9]. Поэтому для их восстановления 
были выбраны такие методики, которые позволяли провести реакции в относительно мягких условиях по схеме Гойина-Робинзона: кислоты $\rightarrow$ эфиры $\rightarrow$ спирты $\rightarrow$ галоидные алкилы $\rightarrow$ углеводороды. Результаты исследований приводятся в экспериментальной части.

\section{Экспериментальная часть}

Получение метиловых эфиров ПФК $\left[{ }^{10,11}\right]$. Исследовались эфирорастворимая и ацетонорастворимая фракция ПФК $\left[{ }^{12}\right]$. В качестве метилирующего агента был выбран диазометан, так как он энергично реагирует при комнатной температуре, метилирует не только кислые, но и гидроксильные группы, водород которых может мешать дальнейшему восстановлению.

Полученные метиловые эфиры представляли собой красновато-коричневые вязкие массы. Результаты анализа их элементного и функционального составов, среднего молекулярного веса (эбулиоскопическим методом в ацетоне) и рассчитанные средние эмпирические формулы приведены в таблице.

Как видно из приведенных данных, диазометан прометилировал практически все карбоксильные и частично гидроксилыные группы; в ацетонорастворимой фракции ПФК не прореагировала $1 / 3$ от исходного количества гидроксилов.

Сравнивая данные элементного анализа до и после метилирования (таблица), можно отметить, что содержание углерода и водорода в эфирах увеличилось, а содержание азота понизилось. Понижение содержания азота в эфирах произошло, возможно, за счет его отщепления в процессе метилирования (в форме азотной или азотистой кислот), что частично подтверждается также уменьшением содержания сложноэфирных групп в полученных эфирах по сравнению с расчетным по функциональному анализу исходных фракций. В эфирорастворимой фракции оно стало меньше на одну группу, а в ацетонорастворимой - на 5,8 группы. Часть несбалансированности по эфирным группам может быть отнесена также за счет осадка, выделяющегося при метилировании; он подробно не анализировался. Количество его было неодинаковым для отдельных фракций. Так, в эфирорастворимой фракции осадок составил $0,87 \%$ от общего выхода продуктов метилирования. Значительный осадок образовался при метилировании ацетонорастворимой фракции ПФК $-16,76 \%$. Образование осадков при метилировании возможно как вследствие понижения растворимости отдельных компонентов смеси, так и в результате побочных реакций $\left[{ }^{13}\right]$. В литературе имеются данные о том, что диазометан присоединяется к двойным связям, вызывает расширение циклов при взаимодействии с циклическими соединениями и пр. Средний молекулярный вес полученных эфиров ниже, чем у исходных кислот: в эфирорастворимой фракции - 520, в ацетонорастворимой - 760. Побочные продукты реакции не мешают дальнейшему исследованию, так как легко отделяются от основного продукта.

Полученные метиловые эфиры ПФК далее восстанавливали до спиртов $\mathrm{LiAlH}_{4}$. Характеристика восстановленных продуктов приводится ниже.

Восстановление метиловых эфиров ПФК $\left[{ }^{14,15}\right]$. Реакция проводилась при избытке $\mathrm{LiAlH}_{4}$ в среде аргона. В процессе восстановления были получены два вида продуктов: растворимые и нерастворимые в смеси тетрагидрофурана и диэтилового эфира (1:1). Растворимые продукты восстановления представляли собой вязкую массу коричневого цвета. 


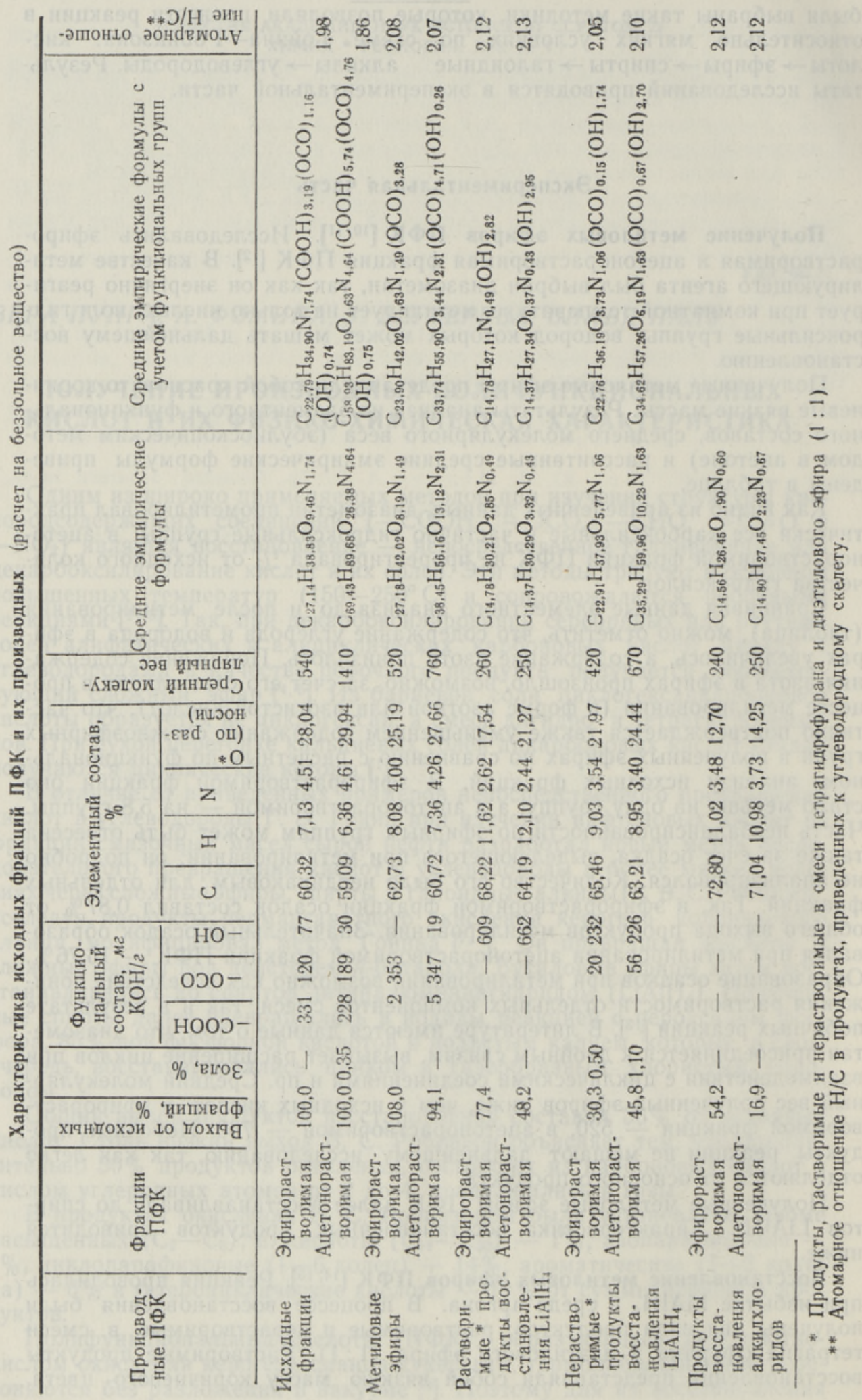


Выход их составлял для эфирорастворимой фракции ПФК 71,7, для ацетонорастворимой - 51,2\% по весу от взятых для реакции метиловых эфиров. Остальная часть органического вещества была связана в виде нерастворимого комплекса. Ее извлекали н-бутанолом при разложении комплекса разбавленной соляной кислотой. По внешнему виду она представляла собой порошки темно-коричневого цвета и по выходу составляла соответственно 28,1 и $48,7 \%$ от. метиловых эфиров эфирорастворимой и ацетонорастворимой фракций ПФК.

Химическая характеристика продуктов восстановления и средний молекулярный вес (эбулиоскопическим методом в метаноле) приведены в таблице.

Полученные продукты восстановления различаются между собой не только по внешнему виду, но и по химическому составу. Растворимые продукты представляют собой относительно низкомолекулярные «спирты» (молекулярный вес вдвое ниже, чем у исходных эфиров) насыщенного характера (атомарное отношение H/C составляет 2,12-2,13). Пробы содержат в среднем на молекулу больше гидроксильных групп $(2,82$ $2,95)$; сложноэфирные группы в них не обнаружены.

Газохроматографическим анализом в растворимых продуктах восстановления был идентифицирован только пропандиол, основную же часть этих продуктов разделить не удалось.

Иная картина наблюдается при рассмотрении органической части нерастворимых комплексов. Ее средний молекулярный вес вдвое выше, чем у растворимых продуктов восстановления. Наиболее сложными по составу являются нерастворимые продукты восстановления ацетонорастворимой фракции ПФК (мол. вес 670).

По элементному составу нерастворимые продукты отличаются от растворимых пониженным содержанием углерода и водорода и более высоким содержанием азота и кислорода. Кроме того, в них найдены сложноэфирные группы, что свидетельствует о неполноте восстановления [15].

Дальнейшему исследованию подвергли только растворимые продукты восстановления, из которых были получены галоидные алкилы. Продукты галоидирования далее восстанавливались на никеле Ренея. Методика галоидирования и восстановления приводится ниже.

Галоидирование и восстановление алкилхлоридов $[1,13,16]$. Галоидные алкилы получали взаимодействием спиртов с тионилхлоридом в присутствии пиридина. При хлорировании алканолов хлористого тионила рекомендуется брать больше $(1,4-2,0$ моля вместо 1,1$)$, так как его избыток препятствует изомеризации алкилхлоридов в присутствии хлористого водорода.

Продукты галоидирования представляли собой порошки почти черного цвета с примесью белых кристаллов. Они без дальнейших анализов далее восстанавливались в щелочном растворе на никеле Ренея. Для восстановления пасту никеля Ренея брали в количестве, в полтора раза превышающем расчетное; щелочь тоже брали в избытке, необходимом для нейтрализации имеющейся в алкилхлоридах соляной кислоты.

Полученные продукты восстановления представляли собой густую массу светло-коричневого цвета. Выход их составлял соответственно 70,0 и $35,0 \%$ по весу от спиртов эфирорастворимой и ацетонорастворимой фракций ПФК. Довольно низкий выход продуктов восстановления можно объяснить тем, что часть низкомолекулярных соединений, вероятно, улетучивается как в форме алкилхлоридов, так и в форме алканов во время вакуумной отгонки растворителей и сушки. 
Характеристика восстановленных продуктов приведена в таблице. Как видно из приведенных данных, полного восстановления до углеводородов в принятых условиях не произошло. В продуктах восстановления содержится относительно много остаточного (нейтрального) кислорода $(12,70-14,25 \%)$. Кроме того, их не удалось растворить в неполярных растворителях и разделить методом газо-жидкостной хроматографии. Поэтому восстановленные продукты далее подвергались пиролитическому расщеплению при температуре $300-400^{\circ}$ в вакууме и при атмосферном давлении. Летучие продукты улавливались охлаждением приемника твердой углекислотой. Выход их составлял до $85 \%$ по весу от исходной пробы в обоих случаях.

Летучие продукты в виде эфирных растворов анализировались на хроматографе УХ-1. Данные хроматографирования показали, что состав летучих продуктов неодинаков: продукты пиролиза в вакууме представляли собой смесь гомологов кислородсодержащих соединений алифатического ряда с длинными цепями и температурой кипения в интервале $200-400^{\circ}$; продукты пиролиза при атмосферном давлении были представлены алифатическими углеводородами, цепи которых содержали от 8 до 14 атомов углерода (рис. 1). Можно предположить, что при нагревании в условиях атмосферного давления происходил разрыв углеродуглеродных связей длинных цепей, который и обнаруживался на хроматограммах в виде двойных парафин-олефиновых пиков.

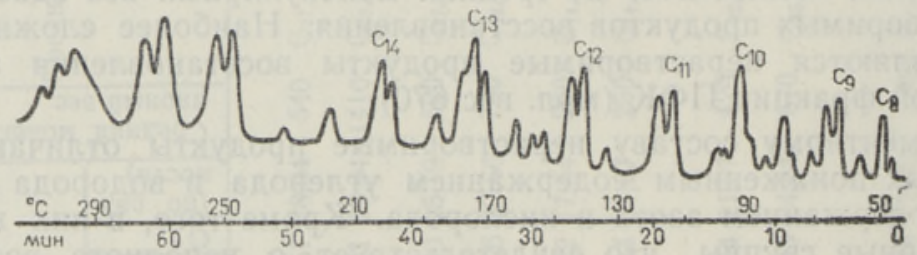

Рис. 1. Разделение на апиезоне $L$ летучих продуктов пиролиза (при атмосферном давлении) восстановленной эфирорастворимой фракцни ПФК.

Об алифатическом характере продуктов восстановления свидетельствуют и данные ИК-спектроскопии, которые приведены ниже.

Спектральный анализ производных ПФК. Для получения дополнительных данных о природе производных ПФК были сняты их инфракрасные спектры на приборе UR-10 (фирмы «Цейс»). Образцы изучались в форме таблеток с бромистым калием; для сравнения спектров между собой не только качественно, но и количественно (относительно), отношение пробы к бромистому калию во всех образцах было одинаковым $(1: 50)$.

Так как спектры исследуемых фракций ПФК отличаются между собой незначительно, то на рис. 2 представлены спектры поглощения только ацетонорастворимой фракции ПФК и всех ее производных. Интерпретация полос поглощения проводилась по нескольким литературным источникам [17-19].

Сравнивая между собой спектры исходных фракций и их производных, можно отметить основные изменения в составе отдельных производных. В спектрах метилированных продуктов отсутствует полоса поглощения в области 930-920 $\mathrm{cm}^{-1}$, характерная для внеплоскостных деформаций гидроксила карбоксильной группы; полоса поглощения спиртовых гидроксилов (1100 и $\left.1050 \mathrm{~cm}^{-1}\right)$ менее выражена, чем в исходных кисло- 
тах, а в спектрах эфирорастворимой фракции вовсе отсутствует, что свидетельствует, по-видимому, о полном их метилировании. В спектрах метиловых эфиров отмечены три новые полосы поглощения в области $1300-$ $1150 \mathrm{~cm}^{-1}$, по данным А. Вайсбергера [ $\left.{ }^{19}\right]$, соответствующие метоксильным группам.

Рис. 2. ИК-спектры исходной ацетонорастворимой фракции ПФК и ее производных:

$a$ - исходные ПФК; 6 - метиловые эфиры ПФК; 8 - нерастворнмые продукты восстановления $\mathrm{LiAlH}_{4} ; 2-$ растворимые продукты восстановления $\mathrm{LiAlH}_{4} ; \partial-$ продукты восстановления алкилхлорндов (таблетки КВr, $2 \%$ вещества).

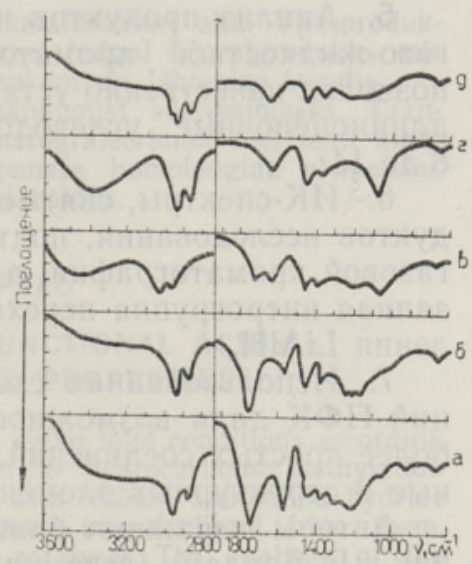

Спектры продуктов восстановления метиловых эфиров («спиртов») отличаются как между собой, так и от спектров исходного и метилированного продуктов. В спектрах нерастворимых продуктов восстановления присутствует полоса поглощения $\left(1720 \mathrm{~cm}^{-1}\right)$, характерная для сложноэфирных групп, что указывает на неполноту восстановления; в растворимых «спиртах» она отсутствует; кроме того, в последних полосы поглощения спиртовых гидроксилов более интенсивно выражены. В спектрах продуктов восстановления отсутствует полоса поглощения нитрогруппы при $1550 \mathrm{cs}^{-1}$, которая имеется в спектрах поглощения исходных фракций ПФК и их метиловых эфиров; появление новой полосы в области $1620 \mathrm{~cm}^{-1}$ отвечает поглощению аминогруппы. Это свидетельствует о том, что произошло восстановление не только сложноэфирных, но и нитрогрупп.

В спектрах продуктов восстановления алкилхлоридов отсутствуют полосы поглощения спиртовых гидроксилов, имеется поглощение аминогруппы.

Полосы поглощения, характерные для метиленовых и метильных групп $\left(2930,2860,1460,1360 \mathrm{cs}^{-1}\right)$ и длинных метиленовых цепочек $\left(720 \mathrm{~cm}^{-1}\right)$, во всех спектрах сохраняются.

\section{Выводы}

1. Проведено последовательное превращение фракций ПФК в сложные эфиры, спирты, галоидалкилы и углеводороды.

2. Установлено, что диазометан практически полностью метилирует кислые и спиртовые группы при комнатной температуре. Однако при этом образуется осадок, количество которого тем больше, чем сложнее продукт метилирования.

3. Восстановление метилированных продуктов эфирорастворимой и ацетонорастворимой фракций $\mathrm{LiAlH}_{4}$ проходит при сравнительно низких температурах, но с различным успехом. Полнее восстанавливаются продукты эфирорастворимой фракции ПФК с одновременным образованием значительных количеств нерастворимых веществ $(28-49 \%)$.

4. Восстановление алкилхлоридов исследуемых фракций на никеле Ренея в щелочной среде не привело к образованию углеводородов, о чем свидетельствует относительно высокое содержание кислорода $(12,70-$ $14,25 \%)$. Выход продуктов восстановления эфирорастворимой фракции составил 54,2 , ацетонорастворимой - $16,9 \%$ от веса исходных фракций ПФК. 
5. Анализ продуктов восстановления путем сочетания пиролиза с газо-жидкостной хроматографией образующихся летучих соединений позволил качественно установить в продуктах деструкции алифатические длинноцепочные углеводороды с количеством атомов углерода от 8 до 14.

6. ИК-спектры, снятые с исходных, промежуточных и конечных продуктов исследования, подтвердили данные функционального анализа и газовой хроматографии, а также позволили заключить, что прочно связанная нитрогруппа переходит в аминогруппу уже на стадии восстановления $\mathrm{LiAlH}_{4}$.

7. Использованная схема превращений сложных по составу фракций ПФК дала возможность получить из них часть вещества в виде более простых соединений, результаты анализа которых дополнили данные о структурных элементах углеводородного скелета ПФК.

Авторы выражают благодарность И. Клесменту, Ю. Риккен, Э. Мянник и Е. Бондарь (газо-жидкостная хроматография), М. Панк и Э. Урбас (спектральный и элементный анализы) за помощь при выполнении работы.

\section{ЛИТЕРАТУ РА}

1. Вейганд-Хильгет аг, Методы эксперимента в органической химии, М., 1969, c. $202-216$; c. $814-823$.

2. Entel J., J. Am. Chem. Soc., 77, 61 (1955).

3. Montgomery R. S., Holly E. D., Fuel, 37, 2, 181 (1958).

4. Old h a m J. W. H., J. Chem. Soc., 100 (1950).

5. Wils on C. V., Org. Reactions, 9, 332 (1957).

6. G o h e en G. E., Industr. Engng Chem. (Industr.), 32, 503 (1940).

7. R ob in son W. S., L a wh or D. L., Fuel, 15, 5, 375 (1961).

8. Organic Geochemistry, Methods and Results, Springer-Verlag, Berlin, New York, 1969 , p. $622-636$.

9. Фомин а А. С., Побуль Л. Я., Д егтере в а 3. А., Природа керогена прибалтийского горючего сланца-кукерсита и его химические сырьевые качества, Таллин, 1965 , с. $119-182$.

10. Chura ĉek J., Drahokonpilova M., Matouŝek P., Komarek K., J. Chromatogr., 11, 493 (1969).

11. Синтез органических препаратов, Сб. 2., М., 1949, с. 174, 373.

12. Пунга В., Фомина А., Дегтерев а З., Палу В., Изв. АН ЭССР, Хим. Геол., $19,195(1970)$.

13. Новые методы препаративной органической химии, М., 1950, с. 91-135, 202-204.

14. Ми чов и ч В., $М$ и ха й лов и ч М., Алюмогидрид лития и его применение в органической химии, М., 1957, с. 28-121.

15. Бартошевич Р., Мечникова-Столярчик В., Опшондек Б., Методы восстановления органических соединений, М., 1960, с. 214-236.

16. Р у женце в а А. К., К олп а ко в а В. В., Ж. аналит. химии, 6, 4, 223-229 (1951).

17. Н а к аниси К., Инфракрасные спектры и строение органических соединений, М., 1965 , c. $24-72$.

18. Белл а м и Л., Инфракрасные спектры сложных молекул, М., 1963.

19. Установление структуры органических соединений физическими и химическими методами, Т. 1, М., 1967, с. 158-200.

$\begin{array}{cc}\text { Институт химии } & \text { Поступила в редакцию } \\ \text { Академии наук Эстонской ССР } & 21 / \mathrm{I} \\ 1\end{array}$

VERA PUNGA, A. FOMINA, Z. DEGTERJOVA, VILJA PALU

\section{POLUFUNKTSIONAALSETE HAPETE DERIVAATIDE SUNTEES JA FUUSIKALIS-KEEMILINE ISELOOMUSTUS}

Polüiunktsionaalsete hapete fraktsioone töödeldi pehmetes tingimustes GoheeniRobinsoni skeemi järgi eesmärgil taandada nad süsivesinikeks. Metüüliti diasometaaniga, estrid taandati alumiiniumhüdriidiga alkoholideks, millest tionüülkloriidiga valmistati 
halogeenderivaadid, viimased aga taandati Raney nikkelkatalüsaatori abil. Vaheproduktide analüüs näitas, et reaktsioonidel tekib märkimisväärsel hulgal kōrvalprodukte, mis vähendavad sihtproduktide saagist seda enam, mida keerukam on lähteaine koostis.

Selgus, et antud tingimustes ei toimu täielikku taandumist süsivesinikeks. Taandamisproduktide täiendava pürolüüsi ja pürolüsaadi kromatografeerimise teel tehti kindlaks alifaatsete süsivesinike ning hapnikuühendite kōrgemate homoloogide olemasolu. Alifaatseid omadusi kinnitas ka produktide IP spektraalanalüüs.

\section{VERA PUNGA, A. FOMINA, Z. DEGTERYOVA, VILJA PALU \\ SYNTHESIS OF DERIVATIVES OF POLYFUNCTIONAL ACIDS AND THEIR PHYSICAL AND CHEMICAL PROPERTIES}

The fractions of polyfunctional acids have been treated under mild conditions according to the Goheen-Robinson scheme in order to reduce them to hydrocarbons: methylation with diazomethane was carried out, esters were reduced with lithium aluminium hydride into alcohols, halogen-derivatives with thionyl chloride were manufactured from them, and they were reduced with the help of the Raney nickel catalyser. The analysis of the intermediate products showed that a considerable number of by-products was formed from the reactions, and the more complicated the composition of the stock, the more they reduce in the final yield.

It was fixed that under given conditions there was no complete reduction to hydrocarbons. By additional pyrolysis of the reduction products and by chromatographic analysis of pyrolisate, the presence of the homologies of hydrocarbons and oxygen-containing compounds of the aliphatic series was determined. The aliphatic properties of the products were also determined by IP spectral analysis. 